\title{
BMJ Open Secondhand smoke (SHS) exposure before and after the implementation of the Tobacco Free Cities (TFC) initiative in five Chinese cities: a pooled cross-sectional study
}

\author{
Zongshuan Duan, ${ }^{1}$ Yu Wang, ${ }^{1}$ Jidong Huang (D) , ${ }^{1}$ Pamela B Redmon, ${ }^{2}$ \\ Michael P Eriksen ${ }^{1}$
}

To cite: Duan Z, Wang Y, Huang J, et al. Secondhand smoke (SHS) exposure before and after the implementation of the Tobacco Free Cities (TFC) initiative in five Chinese cities: a pooled

cross-sectional study. BMJ Open 2020;10:e044570. doi:10.1136/ bmjopen-2020-044570

- Prepublication history and additional material for this paper are available online. To view these files, please visit the journal online (http://dx.doi. org/10.1136/bmjopen-2020044570).

Received 07 September 2020 Revised 03 December 2020 Accepted 07 December 2020

Check for updates

(C) Author(s) (or their employer(s)) 2020. Re-use permitted under CC BY-NC. No commercial re-use. See rights and permissions. Published by BMJ.

${ }^{1}$ School of Public Health, Georgia State University, Atlanta, Georgia, USA

${ }^{2}$ Global Health Institute, Emory University, Atlanta, Georgia, USA

Correspondence to

Dr Jidong Huang;

jhuang17@gsu.edu

\section{ABSTRACT}

Objectives To assess the levels of secondhand smoke (SHS) exposure before and after the implementation of the Tobacco Free Cities (TFC) initiative.

Design City-wide representative, cross-sectional surveys (Tobacco Questions for Surveys, TQS) were conducted in each participating city before and after the implementation of TFC.

Setting Five large Chinese cities (Chengdu, Chongqing, Wuhan, Xiamen and Xi'an) participated in the TFC initiative. Participants A total of 10184 adults participated in the 2015 TQS survey, and 10233 adults participated in the 2018 TQS survey, respectively.

Interventions The TFC initiative, which included targeted media campaigns, educational programmes, implementing city-wide smoke-free policies and providing cessation interventions, was implemented in these five cities between 2015 and 2018.

Main outcome Self-reported past 30-day (P30D) SHS exposure in indoor workplaces, restaurants and homes. Data analysis The pre-TFC and post-TFC SHS exposure levels were compared among all residents and among certain population subgroups. Multivariate logistic regressions were used to estimate the adjusted associations between P30D SHS exposure and individual characteristics.

Results Across all five cities, the overall rate of self-reported P30D SHS exposure declined in indoor workplaces (from $49.6 \%$ (95\% Cl: $46.4 \%$ to $52.8 \%$ ) to $41.2 \%$ (95\% Cl: $37.7 \%$ to $44.7 \%)$ ), restaurants (from $72.4 \%(95 \% \mathrm{Cl}: 69.8 \%$ to $74.9 \%)$ to $61.7 \%(95 \% \mathrm{Cl}$ : $58.7 \%$ to $64.7 \%)$ ) and homes (from $39.8 \%$ (95\% Cl: $36.9 \%$ to $42.7 \%$ ) to $34.7 \%$ (95\% Cl: $31.5 \%$ to $37.8 \%)$ ) from 2015 to 2018. These declines were statistically significant after controlling for individual characteristics. The P3OD SHS exposure was associated with sex, age, education level, occupation and current smoking status. The associations varied by venues.

Conclusions Our analysis showed that compared with the nationwide SHS exposure levels reported in concurrent national surveys, the declines in P30D SHS exposure in five Chinese cities that implemented the TFC initiative were larger in indoor workplaces and restaurants. Our
Strengths and limitations of this study

- Multistage sampling method was applied to select a city-wide representative sample of adults (aged 15 and above) for each of the five Chinese cities that participated in the Tobacco Free Cities (TFC) initiative.

- The Tobacco Questions for Surveys were administered to the study sample in each city to assess the levels of secondhand exposure (SHS) in workplaces, restaurants, and homes before and after the implementation of the TFC initiative.

- The pre-TFC and post-TFC SHS exposure levels were compared among all adult city residents, as well as among certain population subgroups, using multivariate logistic regressions controlling for individual characteristics.

- Limitations of this study included self-reported smoking status and SHS exposure, which may be subject to recall bias and social desirability bias, and the inability to estimate the SHS exposure changes before and after the implementation of the TFC initiative at the individual level using pooled crosssectional surveys

- The associations between SHS exposure and individual level characteristics reported in this study may not be generalised to other cities or rural areas in China.

findings suggest that the TFC initiative was effective in reducing SHS exposure in Chinese cities.

\section{INTRODUCTION}

Secondhand smoke (SHS) exposure is a major preventable cause of diseases for infants, children and non-smoking adults. ${ }^{1-3}$ It has been well documented that there is no risk-free level of exposure to $\mathrm{SHS}^{2}$ As the largest tobacco consumption country globally, China has more than 300 million smokers, exposing an estimated 740 million people 
to harmful environmental tobacco smoke. ${ }^{4}$ According to the findings from a cross-country comparison of past 30-day (P30D) SHS exposure among adults in 14 countries (Bangladesh, Brazil, China, Egypt, India, Mexico, Philippines, Poland, Russia, Thailand, Turkey, Ukraine, Uruguay and Vietnam), China had the highest rates of P30D SHS exposure in indoor workplaces $(63.3 \%)$ and restaurants $(88.5 \%)$ in $2010 .{ }^{5} 6$ In addition, the rate of P30D exposure to SHS at home in China $(67.3 \%)$ was the second highest among these 14 countries, ${ }^{5}$ resulting in more than 164 million children being exposed to SHS at home in $2010 .^{7}$

Recent nationwide surveys showed that exposure to SHS had been declining in China over the last decade. For example, the China Adult Tobacco Survey (CATS) found that from 2015 to 2018, the P30D SHS exposure in indoor places had declined, particularly in homes $(57.1 \%$ to $44.9 \%$ ), workplaces $(54.3 \%$ to $50.9 \%$ ), government buildings $(38.1 \%$ to $31.1 \%)$, healthcare facilities $(36.8 \%$ to $24.4 \%)$, restaurants $(76.3 \%$ to $73.3 \%$ ) and public transportation (16.4\% to $12.9 \%) .{ }^{89}$ Previous studies indicated that the decline in SHS exposure in China was likely due to the implementation of smoke-free air policies in public places in recent years. ${ }^{10}{ }^{11}$ In 2013, the Chinese Central Government issued a notice prohibiting government officials smoking in public to set an example for all to follow. ${ }^{42}$ In 2014, the Ministry of Education and the National Health Commission (now National Health and Family Planning Commission) issued directives for all schools and healthcare facilities in China to become $100 \%$ smoke-free. ${ }^{412}$ To date, more than 20 largest Chinese cities, including Beijing, Shanghai, Shenzhen and Xi'an, have adopted city-wide smoke-free air policies. ${ }^{8}$

Despite progress in smoke-free legislation and tobacco control efforts, to date, there are still no comprehensive smoke-free air laws at the national level in China. The 2015 CATS estimated that more than half $(54.3 \%)$ of adults who worked indoors were still exposed to tobacco smoke at their workplaces, and more than 500 million adults were exposed to SHS at home. ${ }^{13}$ Even in cities where smoke-free air policies have been adopted, the strengths and enforcement of these policies varied significantly at the local level. ${ }^{1415}$ To support Chinese cities to develop effective, comprehensive and sustainable tobacco control programmes, researchers from Georgia State University (GSU) and China Centers for Disease Control and Prevention (China CDC) selected five Chinese cities to participate in the Tobacco Free Cities (TFC) initiative in 2015. The TFC initiative was a 3-year programme aimed to achieve the goal of creating cities where no tobacco use is the norm, by providing grant funds and experts' support to help the cities implement best practice interventions, including adoption of tobacco-free policies, communication strategies to increase knowledge on harms of tobacco use and provision of cessation services. ${ }^{16}$ The research team in GSU collaborated with the ThinkTank Research Center for Health Development, a Chinabased non-governmental organisation, the China CDC and the National Health Commission to identify a non-random sample of 10 potential cities for the TFC initiative in 2015. Five metropolitan cities were selected based on population size, societal influence in China, local government support for tobacco control efforts and stage of readiness to take action to change social norms of tobacco use in their city. These five cities selected were Chengdu, Chongqing, Wuhan, Xiamen and Xi'an. None of these five cities had city-wide smoke-free air policies at the time of selection. The population size of these five participating cities ranged from about 4 million in Xiamen to about 30 million in Chongqing (see online supplemental table 1 for detail).

This study aims to conduct a preliminary assessment of the effectiveness of the TFC initiative in reducing SHS exposure in indoor areas. Studies using the International Tobacco Control (ITC) data indicated that partial smokefree air policies had minimal impact on reducing SHS exposure in indoor workplaces, restaurants and bars in China. ${ }^{10}{ }^{17}$ Although a few small randomised controlled trials had demonstrated the effectiveness of tobacco control intervention programmes in reducing SHS exposure in China, ${ }^{18} 19$ the evidence on the effectiveness of city-wide tobacco control activities in reducing SHS exposure in China is scarce. In addition, because smoking behaviour and its determinants may differ considerably between urban and rural areas in China, the overall SHS exposure status at the national level may mask the differences across regions and population subgroups. ${ }^{2021}$ Importantly, due in part to a lack of representative, citywide data on SHS exposure in China, very little is known about SHS exposure in large cities, where the population is more concentrated than small cities and rural areas, and SHS exposure may be more pronounced. One study using the ITC data from seven cities and five rural areas of China found that from 2009 to 2015, there were no significant differences in SHS exposure between smokers and non-smokers except that SHS exposure among smokers was higher than among non-smokers in rural workplaces. ${ }^{17}$

This study is designed to enrich the literature by examining the level of SHS exposure in indoor workplaces, indoor areas of restaurants, and at home in five large Chinese cities before and after the implementation of the TFC initiative in those cities. This study also investigates the potential differences in SHS exposure across population subgroups. It was hypothesised that the decline in SHS exposure at workplaces, restaurants and homes between 2015 and 2018 would be more pronounced in these five cities with the TFC initiative, compared with the nationwide trend. In addition, the SHS exposure was hypothesised to vary among population subgroups characterised by sociodemographic factors and smoking status.

\section{METHODS}

\section{Study design and survey participants}

The TFC initiative was implemented in the five selected cities, that is, Chengdu, Chongqing, Wuhan, Xiamen and 
Xi'an, from 2015 to $2018 .{ }^{16}$ During this period, these cities executed activities, including implementing city-wide and sector-wide smoke-free policies, launching health education interventions and mass media campaigns, and providing cessation interventions for smokers who want to quit (see online supplemental table 1 for a detailed list of tobacco control activities in each city). Two citywide representative household surveys were conducted in each city, one before the TFC initiative and the second one after the TFC initiative, by the local municipal health department under the supervision of the China CDC. The surveys assessed tobacco use, exposure to SHS, and knowledge, attitudes and beliefs towards various tobacco and nicotine products, using the Tobacco Questions for Surveys (TQS) questionnaire. TQS was a subset of key questions adapted from the Global Adult Tobacco Survey (GATS), developed by the WHO and the US CDC. ${ }^{22}$

The first TQS survey was conducted from October 2015 to March 2016 (data were collected mainly in 2015, referred to as TQS 2015 below). The second TQS survey was conducted from November 2017 to March 2018 (data were collected mainly in 2018, referred to as TQS 2018 below) (see a detailed timeline in online supplemental table 2). Participants were recruited using a householdbased, multistage cluster sampling scheme designed to represent non-institutionalised adults (defined as age 15 years and above at the survey time) residing in urban areas of these five cities, based on the principles outlined in the GATS Sample Design Manual. ${ }^{23}$ Detailed sampling procedures and weight calculations were described in previously published studies. ${ }^{24}{ }^{25}$ The household surveys were conducted through indoor face-to-face interviews using handheld computer-assisted devices to reduce measurement errors. These surveys were approved by the local institutional review board (IRB) of each city's municipal health department. Written informed consent was obtained from all participants. A total of 10184 participants completed the household survey in 2015/2016, and 10233 participants completed the survey in 2017/2018. The response rate and sample size overall for each city were listed in online supplemental table 2. Secondary data analyses were approved by the GSU IRB.

\section{MEASURES AND VARIABLES \\ Outcomes}

The primary outcome variables in this study were selfreported P30D SHS exposure status in indoor areas of workplaces, restaurants and homes. All study participants were asked whether they usually worked indoors. Participants who responded 'yes' were then asked whether they had noticed anyone (including themselves) smoking in indoor areas of workplaces in the past 30 days. In addition, all participants were asked whether they had visited any restaurants in the past 30 days, and if so, whether they had observed anyone (including themselves) smoking inside any of the restaurants they visited in the past 30 days. Finally, all participants were asked whether anyone (including themselves) had smoked in their homes in the past 30 days.

\section{Current tobacco smoking status}

Participants were asked whether they were currently using any smoking tobacco products, including cigarettes, cigars and pipes, daily, occasionally or not at all. Participants who were currently using smoking tobacco products daily or occasionally were categorised as current smokers. Participants who were not using any smoking tobacco products at all were categorised as current non-smokers.

\section{Demographic characteristics}

Demographic variables included biological sex, age, highest education level and occupation type. Age was categorised into 15-24, 25-44, 45-64, and 65 years and older. Education was categorised into primary school completed or below, junior high school completed, senior high school completed, and college degree or above. The occupation was categorised into 'government employee, teacher, healthcare provider', 'factory, business, agriculture and service industry employee', and 'not in the labour force', which included the unemployed, students, homemakers and retired. The TQS survey grouped 'government employee, teacher, healthcare provider' into one single category because most schools and hospitals in China are government-owned. On the contrary, 'factory, business, agriculture and service industry employees' are generally considered working in the private sector in China. The rationale for this grouping method was because existing smoke-free policies in China were generally implemented in government buildings, schools and hospitals. ${ }^{16}$ The categorisation of individual characteristics and the grouping method for occupation were consistent with the method used in other national-level surveys in China, such as the 2015 and 2018 CATS. $^{813}$

\section{Data analyses}

SAS V.9.4 was used for data analyses. Complex sampling procedures were accounted for in analyses by using the survey procedures in SAS. Invalid answers, that is, 'I don't know' and 'Refused', were coded as missing. The main resources of missing data were outcome variables (about $2 \%$ of respondents with missing values for SHS exposure at each venue) and self-reported occupation types (about $1 \%$ of respondents with missing values). The proportion of respondents with missing values on any key variable included in data analyses for each venue was less than $5 \%$. We assumed that missing was at random and used pairwise deletion to handle missing values. ${ }^{26}$ We estimated the percentages and $95 \%$ CIs of urban adult residents who had been exposed to SHS in the past 30 days at selected venues, in total and by demographic characteristics, including biological sex, age, education, occupation and current smoking status. The Rao-Scott $X^{2}$ test was used to check the unadjusted associations between P30D SHS exposure and survey years in total and by demographic characteristics. In addition, multivariate 
logistic regression was used to estimate the adjusted associations between P30D SHS exposure and survey years, controlling for demographic characteristics, including age, gender, education, occupational status and smoking status.

\section{Patient and public involvement}

This study was done without patient involvement. The target population of TQS was non-institutionalised adults residing in urban areas of the five participating Chinese cities.

\section{RESULTS}

\section{Demographic characteristics and smoking status}

Among urban adult residents in all five participating cities, in 2015 , about $11 \%$ of them completed primary school or below, and $37 \%$ had a college degree or above. Approximately $11 \%$ worked as government employees, teachers or healthcare providers, and $44 \%$ were not in the labour force. In 2018, approximately 9\% completed primary school or below, and $42 \%$ had a college degree or above. There were about $11 \%$ of adult residents working as government employees, teachers or healthcare providers, and more than half of them $(51 \%)$ were not in the labour force. Approximately 23\% of them were current smokers in 2015 and 2018 (online supplemental table 3).

\section{P30D SHS exposure in indoor workplaces}

As shown in table 1, 4710 and 5011 respondents usually worked indoors and reported P30D SHS exposure status in 2015 and 2018, respectively. The overall P30D SHS exposure in indoor workplaces decreased from $49.6 \%$ (95\% CI: $46.4 \%$ to $52.9 \%$ ) in 2015 to $41.2 \%$ (95\% CI: $37.7 \%$ to $44.7 \%)$ in 2018 ( $\mathrm{p}=0.0003)$. In $2015,58.3 \%(95 \%$ CI: $54.5 \%$ to $62.0 \%$ ) of men and $39.2 \%$ (95\% CI: $35.8 \%$ to $42.7 \%$ ) of women reported P30D SHS exposure, while $49.2 \%$ (95\% CI: $45.1 \%$ to $53.2 \%$ ) of men and $32.2 \%$ (95\% CI: $28.4 \%$ to $36.0 \%$ ) reported P30D SHS exposure in their indoor workplaces in 2018 ( $p=0.0007$ and $p=0.0055$ for men and women, respectively). Regarding age, the rate of P30D SHS exposure was the highest among adults aged 45-64 years old in 2015 and 2018. From 2015 to 2018, the decline in P30D SHS exposure was statistically significant for adults aged 25-44 years old (47.9\%, 95\% CI: $44.4 \%$ to $51.4 \%$ vs $41.2 \%, 95 \%$ CI: $37.4 \%$ to $45.0 \%, \mathrm{p}=0.0086$ ) and $45-64$ years old $(58.6 \%, 95 \%$ CI: $53.9 \%$ to $63.3 \%$ vs $46.9 \%$, $95 \%$ CI: $42.0 \%$ to $51.8 \%$, $\mathrm{p}=0.0005)$. Exposure to SHS followed a gradient, that is, exposure decreases as education levels increase, in both 2015 and 2018 surveys. The decline in P30D SHS exposure was statistically significant for people with senior high school completed or above $(51.5 \%, 95 \%$ CI: $46.8 \%$ to $56.2 \%$ vs $44.6 \%, 95 \%$ CI: $40.0 \%$ to $49.1 \%, \mathrm{p}=0.0356$ ) and college degree or above

Table 1 Past 30-day secondhand smoke exposure in indoor workplaces before and after the implementation of the Tobacco Free Cities initiative in all five participating Chinese cities in 2015 and 2018

\begin{tabular}{|c|c|c|c|c|c|}
\hline \multirow[b]{2}{*}{ Demographic characteristics } & \multicolumn{2}{|l|}{$\begin{array}{l}\text { Year } 2015 \\
(\mathrm{~N}=4710)\end{array}$} & \multicolumn{2}{|l|}{$\begin{array}{l}\text { Year } 2018 \\
(\mathrm{~N}=5011)\end{array}$} & \multirow[b]{2}{*}{$P$ value } \\
\hline & Per cent & $95 \% \mathrm{Cl}$ & Per cent & $95 \% \mathrm{Cl}$ & \\
\hline Total & 49.61 & 46.37 to 52.85 & 41.24 & 37.74 to 44.74 & 0.0003 \\
\hline \multicolumn{6}{|l|}{ Sex } \\
\hline Male & 58.25 & 54.52 to 61.98 & 49.15 & 45.13 to 53.18 & 0.0007 \\
\hline Female & 39.23 & 35.8 to 42.66 & 32.21 & 28.39 to 36.03 & 0.0055 \\
\hline \multicolumn{6}{|l|}{ Age (years) } \\
\hline $15-24$ & 44.83 & 39.31 to 50.35 & 37.34 & 31.34 to 43.34 & 0.0717 \\
\hline $25-44$ & 47.88 & 44.4 to 51.35 & 41.21 & 37.41 to 45.01 & 0.0086 \\
\hline $45-64$ & 58.58 & 53.87 to 63.3 & 46.88 & 42.01 to 51.75 & 0.0005 \\
\hline 65 and above & 41.66 & 20.05 to 63.26 & 25.39 & 16.05 to 34.74 & 0.1183 \\
\hline \multicolumn{6}{|l|}{ Education level } \\
\hline Primary school completed or below & 64.16 & 54.51 to 73.8 & 52.85 & 42.17 to 63.53 & 0.1071 \\
\hline Junior high school completed & 56.33 & 50.59 to 62.06 & 48.05 & 41.63 to 54.46 & 0.0511 \\
\hline Senior high school completed & 51.47 & 46.76 to 56.17 & 44.57 & 40.02 to 49.11 & 0.0356 \\
\hline College degree or above & 45.81 & 42.33 to 49.29 & 37.25 & 33.05 to 41.44 & 0.0012 \\
\hline \multicolumn{6}{|l|}{ Occupation } \\
\hline Government employee, teacher, healthcare provider & 39.39 & 33.96 to 44.82 & 30.43 & 24.89 to 35.97 & 0.0304 \\
\hline Factory, business, service industry employee & 52.22 & 49.02 to 55.42 & 44.08 & 40.21 to 47.95 & 0.0003 \\
\hline \multicolumn{6}{|l|}{ Current smoking status } \\
\hline Yes & 70.65 & 65.99 to 75.31 & 63.59 & 59.06 to 68.12 & 0.0313 \\
\hline No & 42.76 & 39.39 to 46.14 & 34.59 & 30.97 to 38.22 & 0.0007 \\
\hline
\end{tabular}


Table 2 Past 30-day secondhand smoke exposure in indoor areas of restaurants before and after the implementation of the Tobacco Free Cities initiative in all five participating Chinese cities in 2015 and 2018

\begin{tabular}{|c|c|c|c|c|c|}
\hline \multirow[b]{2}{*}{ Demographic characteristics } & \multicolumn{2}{|l|}{$\begin{array}{l}\text { Year } 2015 \\
(\mathrm{~N}=6576)\end{array}$} & \multicolumn{2}{|c|}{$\begin{array}{l}\text { Year } 2018 \\
(\mathrm{~N}=6878)\end{array}$} & \multirow[b]{2}{*}{$P$ value } \\
\hline & Per cent & $95 \% \mathrm{Cl}$ & Per cent & $95 \% \mathrm{Cl}$ & \\
\hline Total & 72.37 & 69.81 to 74.92 & 61.70 & 58.66 to 64.74 & $<0.0001$ \\
\hline \multicolumn{6}{|l|}{ Sex } \\
\hline Male & 77.37 & 74.76 to 79.98 & 66.00 & 62.57 to 69.43 & $<0.0001$ \\
\hline Female & 66.27 & 62.99 to 69.55 & 56.88 & 53.44 to 60.31 & $<0.0001$ \\
\hline \multicolumn{6}{|l|}{ Age (years) } \\
\hline $15-24$ & 71.56 & 67.35 to 75.76 & 55.37 & 50.74 to 59.99 & $<0.0001$ \\
\hline $25-44$ & 73.00 & 69.98 to 76.03 & 63.47 & 60.12 to 66.82 & $<0.0001$ \\
\hline $45-64$ & 74.56 & 71.21 to 77.91 & 64.80 & 60.21 to 69.38 & 0.0004 \\
\hline 65 and above & 59.40 & 54.2 to 64.59 & 59.36 & 52.74 to 65.98 & 0.9931 \\
\hline \multicolumn{6}{|l|}{ Education level } \\
\hline Primary school completed or below & 64.63 & 58.59 to 70.67 & 69.92 & 64.04 to 75.79 & 0.2197 \\
\hline Junior high school completed & 73.59 & 70.44 to 76.75 & 64.95 & 59.17 to 70.74 & 0.0074 \\
\hline Senior high school completed & 73.37 & 70.03 to 76.7 & 61.10 & 57.44 to 64.75 & $<0.0001$ \\
\hline College degree or above & 72.15 & 69.05 to 75.25 & 60.04 & 56.52 to 63.57 & $<0.0001$ \\
\hline \multicolumn{6}{|l|}{ Occupation } \\
\hline $\begin{array}{l}\text { Government employee, teacher, healthcare } \\
\text { provider }\end{array}$ & 71.71 & 66.38 to 77.04 & 58.8 & 52.5 to 65.11 & 0.0010 \\
\hline Factory, business, service industry employee & 74.96 & 72.35 to 77.58 & 64.92 & 61.5 to 68.33 & $<0.0001$ \\
\hline Not in the labour force ${ }^{\star}$ & 69.22 & 65.5 to 72.93 & 60.09 & 56.2 to 63.98 & 0.0008 \\
\hline \multicolumn{6}{|l|}{ Current smoking status } \\
\hline Yes & 83.55 & 80.48 to 86.62 & 74.33 & 70.13 to 78.54 & $<0.0001$ \\
\hline No & 68.57 & 65.77 to 71.38 & 57.40 & 54.23 to 60.57 & 0.0002 \\
\hline
\end{tabular}

${ }^{*}$ Respondents who were not in the labour force included students, homemakers, retired and unemployed residents either able or unable to work.

( $45.8 \%, 95 \%$ CI: $42.3 \%$ to $49.3 \%$ vs $37.2 \%, 95 \%$ CI: $33.1 \%$ to $41.4 \%, \mathrm{p}=0.0012)$. A significant decrease in the selfreported P30D SHS exposure was observed for both government employees, teachers or healthcare providers, and factory, business and service industry employees. In $2015,70.7 \%$ (95\% CI: $66.0 \%$ to $75.3 \%$ ) of smokers and $42.8 \%$ (95\% CI: $39.4 \%$ to $46.1 \%$ ) of non-smokers reported exposed to SHS at their indoor workplace in the past 30 days, and the corresponding rates in 2018 significantly decreased to $63.6 \%$ (95\% CI: $59.1 \%$ to $68.1 \%$ ) and $34.6 \%$ (95\% CI: $31.0 \%$ to $38.2 \%$ ) for smokers and nonsmokers, respectively.

\section{P30D SHS exposure in indoor areas of restaurants}

As shown in table 2, 6576 and 6878 respondents had visited any indoor areas of restaurants in the past 30 days and reported SHS exposure status in 2015 and 2018, respectively. The overall P30D SHS exposure in indoor areas of restaurants decreased significantly from $72.4 \%$ (95\% CI: $69.8 \%$ to $74.9 \%$ ) in 2015 to $61.7 \%$ (95\% CI: $58.7 \%$ to $64.7 \%)$ in $2018(\mathrm{p}<0.0001)$. Both men and women reported significantly less exposure to SHS from
2015 to 2018 (for men: $77.4 \%$, 95\% CI: $74.8 \%$ to $80.0 \%$ vs $66.0 \%$, $95 \%$ CI: $62.6 \%$ to $69.4 \%$, p $<0.0001$; for women: $66.3 \%, 95 \%$ CI: $63.0 \%$ to $69.6 \%$ vs $56.9 \%, 95 \%$ CI: $53.4 \%$ to $60.3 \%, \mathrm{p}<0.0001)$. In addition, the rate of reporting P30D SHS exposure in indoor areas of restaurants had declined significantly for people in age groups below 65 years old but remained the same $(59.4 \%)$ for residents who were 65 years old or above from 2015 to 2018. In 2015 , adults with primary school completed or below had the lowest rate $(64.6 \%, 95 \%$ CI: $58.6 \%$ to $70.7 \%)$ of reporting P30D SHS exposure in indoor areas of restaurants in 2015. However, this group reported the highest rate $(69.9 \%, 95 \%$ CI: $64.0 \%$ to $75.8 \%)$ in 2018 . The rate of reporting P30D SHS exposure declined significantly in another three education level groups. In addition, respondents in all three occupation categories had experienced a significant decline in P30D SHS exposure in indoor areas of restaurants. In 2015, 83.6\% (95\% CI: $80.5 \%$ to $86.6 \%)$ of current smokers and $68.6 \%(95 \%$ CI: $65.8 \%$ to $71.4 \%$ ) of current non-smokers reported P30D SHS exposure in indoor areas of restaurants, and 
Table 3 Past 30-day secondhand smoke exposure at home before and after the implementation of the Tobacco Free Cities initiative in all five participating Chinese cities in 2015 and 2018

\begin{tabular}{|c|c|c|c|c|c|}
\hline \multirow[b]{2}{*}{ Demographic characteristics } & \multicolumn{2}{|l|}{$\begin{array}{l}\text { Year } 2015 \\
(\mathrm{~N}=9943)\end{array}$} & \multicolumn{2}{|c|}{$\begin{array}{l}\text { Year } 2018 \\
(\mathrm{~N}=10086)\end{array}$} & \multirow[b]{2}{*}{$P$ value } \\
\hline & Per cent & $95 \% \mathrm{Cl}$ & Per cent & $95 \% \mathrm{Cl}$ & \\
\hline Total & 39.80 & 36.89 to 42.71 & 34.65 & 31.49 to 37.81 & 0.0178 \\
\hline \multicolumn{6}{|l|}{ Sex } \\
\hline Male & 44.58 & 41.19 to 47.97 & 41.36 & 37.37 to 45.35 & 0.2293 \\
\hline Female & 34.73 & 31.65 to 37.8 & 27.70 & 24.82 to 30.58 & 0.0009 \\
\hline \multicolumn{6}{|l|}{ Age (years) } \\
\hline $15-24$ & 42.70 & 37.81 to 47.6 & 37.56 & 32.86 to 42.26 & 0.1412 \\
\hline $25-44$ & 37.40 & 34.06 to 40.73 & 31.87 & 27.97 to 35.78 & 0.0327 \\
\hline $45-64$ & 43.30 & 39.87 to 46.72 & 38.33 & 34.37 to 42.28 & 0.0627 \\
\hline 65 and above & 33.94 & 30.51 to 37.37 & 28.79 & 24.65 to 32.93 & 0.0612 \\
\hline \multicolumn{6}{|l|}{ Education level } \\
\hline Primary school completed or below & 43.35 & 38.55 to 48.14 & 39.85 & 33.74 to 45.97 & 0.3936 \\
\hline Junior high school completed & 43.10 & 39.26 to 46.93 & 40.09 & 35.62 to 44.56 & 0.3224 \\
\hline Senior high school completed & 43.78 & 40.23 to 47.32 & 39.24 & 35.22 to 43.27 & 0.0974 \\
\hline College degree or above & 33.81 & 30.35 to 37.26 & 27.71 & 24.87 to 30.54 & 0.0052 \\
\hline \multicolumn{6}{|l|}{ Occupation } \\
\hline $\begin{array}{l}\text { Government employee, teacher, healthcare } \\
\text { provider }\end{array}$ & 31.63 & 26.29 to 36.98 & 30.81 & 26.11 to 35.51 & 0.7085 \\
\hline Factory, business, service industry employee & 41.63 & 38.18 to 45.08 & 35.96 & 32.03 to 39.9 & 0.0299 \\
\hline Not in the labour force* & 39.96 & 36.97 to 42.95 & 34.64 & 30.97 to 38.30 & 0.0288 \\
\hline \multicolumn{6}{|l|}{ Current smoking status } \\
\hline Yes & 74.61 & 71.09 to 78.12 & 72.07 & 68.01 to 76.12 & 0.3518 \\
\hline No & 29.38 & 26.63 to 32.13 & 23.15 & 20.45 to 25.85 & 0.0015 \\
\hline
\end{tabular}

*Respondents who were not in the labour force included students, homemakers, retired and unemployed residents either able or unable to work.

the rates significantly decreased to $74.3 \%$ (95\% CI: $70.1 \%$ to $78.5 \%$ ) and $57.40 \%$ (95\% CI: $54.2 \%$ to $60.6 \%$ ) in 2018 for current smokers and non-smokers, respectively $(\mathrm{p}<0.0001$ and $\mathrm{p}=0.0002$, respectively).

\section{P30D SHS exposure at home}

As shown in table 3, 9943 and 10086 respondents reported P30D SHS exposure status at home in 2015 and 2018, respectively. The overall exposure to SHS in the past 30 days at home decreased significantly from $39.8 \%(95 \%$ CI: $36.9 \%$ to $42.7 \%$ ) in 2015 to $34.7 \%$ (95\% CI: $31.5 \%$ to $37.8 \%)$ in $2018(\mathrm{p}=0.0178)$. The decline was only significant for women $(34.7 \%$, $95 \%$ CI: $31.6 \%$ to $37.8 \%$ vs $27.7 \%$, $95 \%$ CI: $24.8 \%$ to $30.6 \%, p=0.0009$ ), not for men. Regarding age, the rate of self-reported P30D SHS exposure at home was found to be declining in all age groups, but the decline was statistically significant only among 25-44 years old age group (37.4\%, 95\% CI: $34.1 \%$ to $40.7 \%$ vs $31.9 \%$, $95 \%$ CI: $28.0 \%$ to $35.8 \%, \mathrm{p}=0.0327)$. The rate of reporting P30D SHS exposure at home was found declining among urban residents of all education levels, but the decline was statistically significant only among residents with a college degree or above $(33.8 \%, 95 \% \mathrm{CI}$ : $30.4 \%$ to $37.3 \%$ vs $27.7 \%$, 95\% CI: $24.9 \%$ to $30.5 \%$, $\mathrm{p}=0.0052$ ). The rate of self-reported P30D SHS exposure at home was lowest among government employees, teachers or healthcare providers, and did not change significantly from 2015 to 2018 ( $\mathrm{p}=0.7085$ ). A significant decrease in the rate of reporting P30D SHS exposure at home was observed for adults working in factory, business and service industry $(41.6 \%, 95 \%$ CI: $38.2 \%$ to $45.1 \%$ vs $36.0 \%, 95 \%$ CI: $32.0 \%$ to $39.9 \%, p=0.0299$ ), and who were not in the labour force $(40.0 \%, 95 \%$ CI: $37.0 \%$ to $43.0 \%$ vs $34.6 \%, 95 \%$ CI: $31.0 \%$ to $38.3 \%, \mathrm{p}=0.0288$ ) from 2015 to 2018. During the same period, there was a statistically significant decline of reported P30D SHS exposure at home for current non-smokers $(29.4 \%, 95 \%$ CI: $26.6 \%$ to $32.1 \%$ vs $23.2 \%$, $95 \%$ CI: $20.5 \%$ to $25.9 \%$, $\mathrm{p}=0.0015$ ), the decline was not significant for current smokers.

Adjusted ORs of P30D SHS exposure at workplaces, restaurants and homes

Table 4 presented adjusted ORs (aORs) between SHS exposure and survey year, sociodemographic 
Table 4 Adjusted ${ }^{*}$ ORs between past 30-day secondhand smoke exposure and survey year, sociodemographic characteristics and smoking status in indoor workplaces, indoor areas of restaurants and homes in all five Chinese cities participating the Tobacco Free Cities initiative in 2015 and 2018

\begin{tabular}{|c|c|c|c|c|c|c|}
\hline \multirow[b]{2}{*}{ Indicators } & \multicolumn{2}{|c|}{$\begin{array}{l}\text { Workplaces } \\
(\mathrm{n}=9587)\end{array}$} & \multicolumn{2}{|c|}{$\begin{array}{l}\text { Restaurants } \\
(n=13239)\end{array}$} & \multicolumn{2}{|c|}{$\begin{array}{l}\text { Home } \\
(n=19712)\end{array}$} \\
\hline & OR & $95 \% \mathrm{Cl}$ & OR & $95 \% \mathrm{Cl}$ & OR & $95 \% \mathrm{Cl}$ \\
\hline \multicolumn{7}{|l|}{ Year } \\
\hline 2015 & Ref & & Ref & & Ref & \\
\hline 2018 & 0.71 & 0.58 to 0.88 & 0.63 & 0.52 to 0.75 & 0.76 & 0.63 to 0.93 \\
\hline \multicolumn{7}{|l|}{ Sex } \\
\hline Male & 1.53 & 1.32 to 1.76 & 1.24 & 1.11 to 1.38 & 0.59 & 0.51 to 0.68 \\
\hline Female & Ref & & Ref & & Ref & \\
\hline \multicolumn{7}{|l|}{ Age group } \\
\hline $15-24$ & 1.77 & 0.79 to 3.98 & 1.15 & 0.91 to 1.45 & 2.06 & 1.67 to 2.55 \\
\hline $25-44$ & 1.62 & 0.73 to 3.60 & 1.31 & 1.08 to 1.59 & 1.25 & 1.04 to 1.50 \\
\hline $45-64$ & 1.85 & 0.84 to 4.07 & 1.35 & 1.10 to 1.65 & 1.21 & 1.05 to 1.40 \\
\hline 65 and above & Ref & & Ref & & Ref & \\
\hline \multicolumn{7}{|l|}{ Education } \\
\hline Primary school completed or below & Ref & & Ref & & Ref & \\
\hline Junior high school completed & 0.65 & 0.45 to 0.95 & 1.02 & 0.82 to 1.26 & 0.82 & 0.69 to 0.96 \\
\hline Senior high school completed & 0.62 & 0.44 to 0.89 & 0.93 & 0.75 to 1.16 & 0.77 & 0.65 to 0.91 \\
\hline College degree or above & 0.50 & 0.34 to 0.74 & 0.91 & 0.73 to 1.14 & 0.52 & 0.43 to 0.63 \\
\hline \multicolumn{7}{|l|}{ Occupation } \\
\hline Government employee, teacher, healthcare provider & Ref & & 1.01 & 0.83 to 1.23 & 0.86 & 0.71 to 1.04 \\
\hline Factory, business, service industry employee & 1.56 & 1.32 to 1.85 & 1.17 & 1.02 to 1.35 & 0.98 & 0.86 to 1.13 \\
\hline Not in the labour force $\dagger$ & & & Ref & & Ref & \\
\hline \multicolumn{7}{|l|}{ Current smoking status } \\
\hline Yes & 2.21 & 1.84 to 2.65 & 1.88 & 1.59 to 2.21 & 11.27 & 9.62 to 13.20 \\
\hline No & Ref & & Ref & & Ref & \\
\hline
\end{tabular}

*Multivariate logistic regression models were used to estimate the adjusted ORs, controlling survey year, sex, age, education, occupation and current smoking status.

†Respondents who were not in the labour force included students, homemakers, retired and unemployed residents either able or unable to work.

characteristics and smoking status using multivariate logistic regressions. Urban adult residents from all five cities were significantly less likely to report P30D SHS exposure in indoor workplaces $(\mathrm{aOR}=0.71,95 \% \mathrm{CI}$ : 0.58 to 0.88$)$, indoor areas of restaurants $(\mathrm{aOR}=0.63,95 \% \mathrm{CI}$ : 0.52 to 0.75$)$ and at home (aOR=0.76, 95\% CI: 0.63 to 0.93 ) in 2018 compared with in 2015. Men were more likely to report P30D SHS exposure in indoor workplaces $(\mathrm{aOR}=1.53,95 \% \mathrm{CI}: 1.32$ to 1.76$)$ and indoor areas of restaurants (aOR=1.24, 95\% CI: 1.11 to 1.38$)$, but less likely to report P30D SHS exposure at home $(\mathrm{aOR}=0.59$, 95\% CI: 0.51 to 0.68 ) than women. Compared with adults aged 65 years or above, adults in younger age groups were more likely to report P30D SHS exposure in indoor areas of restaurants and at home. In addition, adults with higher education levels were less likely to report P30D SHS exposure in in door workplaces and homes compared with adults with primary school completed or below. Compared with government employees, teachers or healthcare providers, people who worked in factories, businesses and service industries were more likely to be exposed to workplace SHS in the past 30 days $(\mathrm{aOR}=1.56,95 \%$ CI: 1.32 to 1.85$)$. In addition, current smokers were found significantly more likely to be exposed to SHS than their non-smoking counterparts in indoor workplaces $(\mathrm{aOR}=2.21,95 \%$ CI: 1.84 to 2.65$)$, indoor areas of restaurants $(\mathrm{aOR}=1.88,95 \% \mathrm{CI}$ : 1.59 to 2.21) and at home (aOR=11.27, 95\% CI: 9.62 to 13.20$)$ in the past 30 days. Subgroup analyses results by sex and current smoking status were presented in online supplemental tables 4-9. Generally, there were no significant differences in SHS exposure changes between men and women, and between current smokers and non-smokers, controlling for other covariates. City-specific analyses results were presented in online supplemental tables 10-12. Again, no significant differences were found 
Table 5 Secondhand smoke exposure in indoor workplaces, indoor areas of restaurants and homes in 2015 and 2018 nationwide in China and in the five Chinese cities participated in the Tobacco Free Cities (TFC) initiative

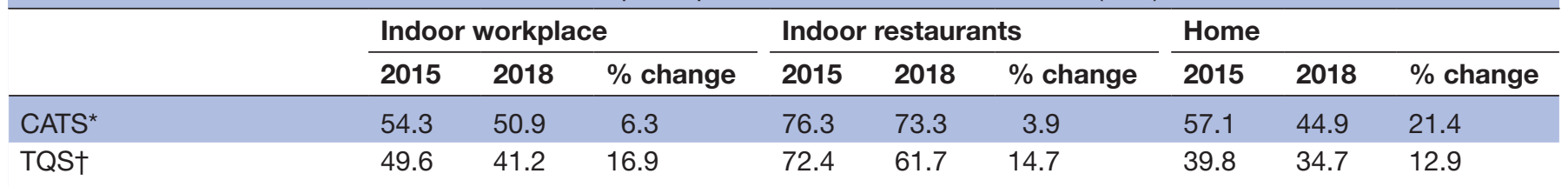

${ }^{*}$ CATS, China Adult Tobacco Survey, conducted in 2015 and 2018, consisted of a representative sample of adults in China.

†TQS, Tobacco Questions for Survey, conducted in 2015 and 2018 in the five Chinese cities participated in the TFC initiative consisted of a representative sample of adult urban residents in these five cities.

across cities in terms of SHS exposure changes between 2015 and 2018.

\section{DISCUSSION}

This study analysed data from two city-wide representative household surveys conducted before and after the implementation of the TFC initiative in five participating Chinese cities. Our study results showed that across all five Chinese cities, the rates of P30D SHS exposure declined significantly in indoor workplaces, indoor areas of restaurants and homes from 2015 to 2018. In addition, compared with the overall levels of P30D SHS exposure reported in the nationwide surveys over the same time period, ${ }^{813}$ the decline of P30D SHS exposure in indoor workplaces and indoor areas of restaurants was significantly larger in these five TFC cities (see table 5), indicating the potential effectiveness of the TFC initiative in reducing SHS exposure in public indoor areas in large Chinese cities. The decline in SHS exposure in workplaces, restaurants and homes in China was similar to those observed in other Asian countries that have adopted smoke-free policies over the past decade. ${ }^{27}$ It is notable that the decrease in SHS exposure at home in our five study cities (from $39.8 \%$ to $34.7 \%$ ) was less than that at the national level (from $57.1 \%$ to $44.9 \%$ ) between 2015 and 2018, and that smoking prevalence did not change in these five cities from 2015 to 2018 despite the TFC initiative. Although these results were consistent with the hypothesis of substitution of smoking in public indoor places with home smoking because of the implementation of smoke-free policies at public indoor places, ${ }^{28} 29$ individual level longitudinal data are needed to examine whether prohibiting smoking in public indoor places had the unintended consequences of increasing smoking at home.

Our results also showed that the change of P30D SHS exposure between 2015 and 2018 varied across population subgroups characterised by demographic and socioeconomic characteristics and smoking status. For example, although the P30D SHS exposure in indoor areas of restaurants did not change among adult urban residents with primary school completed or below between 2015 and 2018, it decreased significantly for those with higher education levels during the same period. Given that education level was positively correlated with socioeconomic status (SES), respondents with higher SES may be more likely to dine in restaurants that were more likely to have smoke-free air policies, or the policies were better implemented/enforced. The subgroup analysis in our study revealed important variations in P30D SHS exposure that were not reported by previous national surveys, which only reported P30D SHS exposure at the national level.

In addition, our study found that the associations between P30D SHS exposure and individual characteristics varied by venue, which contributes to the existing literature that has so far focused primarily on SHS exposure in homes and in overall public indoor areas in China. Consistent with previous findings, our study also found that, in general, being younger, having lower levels of education and being current smokers were associated with higher rates of SHS exposure. ${ }^{11} 3031$ As discussed previously, age and education level were usually positively associated with income or SES, therefore, younger respondents or respondents having lower levels of education may be more likely to work, dine or live in places that had higher rates of smoking, hence more likely to be exposed to SHS. Smokers may be more likely to have peers who smoke, therefore exposing themselves to the SHS produced by their smoking peers. In addition, smokers would be exposed to SHS if they themselves smoked in workplaces, restaurants and their homes. Our study further revealed that the strengths of the associations varied by venue. For example, the association between smoking status and SHS exposure at home was much stronger than in restaurants (aOR: 11.27 vs 1.88 ). This may be due to the fact that home smoking restrictions are not common in China. ${ }^{32} 33$

Furthermore, our study found that men were significantly more likely to be exposed to SHS than women in workplaces and restaurants, but less likely to be exposed at home, controlling for survey year and other individual characteristics. Previous studies also indicated that men were more likely to be exposed to SHS generally, ${ }^{34}$ but women were more likely to be exposed to SHS at home. ${ }^{35}$ Given the disproportional high smoking prevalence among men in China (about 50\% for men and 2\% for women),${ }^{8}$ these findings suggested that many married women in China were exposed to SHS at home because of their smoking husbands. A decline in SHS exposure at home could be expected if more Chinese male smokers 
quit smoking as China further strengthens its tobacco control policies.

It is worth noting that compared with people who were government employees, teachers and healthcare providers, people who worked in factories, businesses and service industries were found to be more likely to be exposed to SHS at workplaces, controlling for the survey year and other individual characteristics. This difference, which was not identified by previous studies, could be partially attributed to the implementation of nationallevel smoke-free policies in government buildings, healthcare facilities and schools. ${ }^{4813}$

Our study provided important evidence to support the implementation of tobacco control interventions, such as the TFC initiative, which included implementing smokefree policies, health education/mass media campaigns and cessation interventions. Our results show that these interventions have the potential to reduce SHS exposure in indoor public places, such as workplaces and restaurants. Although SHS exposure had decreased in China from 2015 to 2018, the prevalence of smoking among men and SHS exposure of all population subgroups is still alarmingly high in China. China ratified the WHO Framework Convention on Tobacco Control in 2005, ${ }^{36}$ which required universal protection of SHS exposure in public indoor places. ${ }^{37}$ Unfortunately, to date, China still does not have a nationwide comprehensive smokefree air policy to prevent SHS exposure in public indoor areas. In Chinese cities where smoke-free policies have been adopted, the strengths of policies and the enforcement of such policies varied significantly. ${ }^{1415}$ The findings of our study indicated that, in the absence of a national level smoke-free policy, cities can play an important role in local tobacco control and protect their residents from the harm of SHS through adoption of comprehensive, strong, and well-enforced city-wide tobacco control policies and programmes.

Our study has limitations. First, the associations between SHS exposure and individual level characteristics were estimated based on data from surveys conducted in five participating cities, therefore, our results may not be generalised to other cities or rural areas in China. Second, smoking status and SHS exposure at three venues were self-reported, which may suffer from recall bias and social desirability bias. ${ }^{38} 39$ In addition, since the data we used were from pooled cross-sectional surveys, we were not able to estimate changes of SHS exposure before and after the implementation of the TFC initiative at the individual level.

\section{CONCLUSION}

The P30D SHS exposure in indoor workplaces, restaurants and homes decreased significantly in five large Chinese cities that implemented the TFC initiative between 2015 and 2018. The TFC initiative activities include city-wide smoke-free policies in public indoor venues, targeted media and education campaigns and cessation interventions effort to help smokers quit. Exposure to SHS in China can be further reduced by expanding the TFC initiative to other Chinese cities without comprehensive tobacco control policies/programmes.

Acknowledgements Technical assistance was provided by China CDC, Chengdu Institute of Health Education, Wuhan Institute of Health Education, Xiamen CDC, Xi'an Institute of Health Education, the ThinkTank Research Center for Health Development and RTI International.

Contributors JH and PBR - conceptualisation. JH, ZD and YW-methodology. PBR - data collection. ZD and YW-formal analysis. ZD and YW-writing (original draft preparation). JH, ZD, YW and PBR — writing (review and editing). ME and PBR — project administration. ME and PBR—-funding acquisition. All authors have read and agreed to the published version of the manuscript.

Funding This work was supported by Pfizer through a grant from the China Tobacco Control Partnership (grant numbers CON009013).

Disclaimer The funders had no role in the design of the study; in the collection, analyses or interpretation of data; in the writing of the manuscript or in the decision to publish the results. The content is solely the responsibility of the authors and does not necessarily represent the official view of Pfizer or the China Tobacco Control Partnership.

Competing interests None declared.

Patient consent for publication Not required.

Provenance and peer review Not commissioned; externally peer reviewed.

Data availability statement Data are available upon reasonable request. Data may be obtained from a third party and are not publicly available. All data relevant to the study are included in the article or uploaded as supplemental information. De-identified study data can be accessed through a written request to the TFC initiative.

Supplemental material This content has been supplied by the author(s). It has not been vetted by BMJ Publishing Group Limited (BMJ) and may not have been peer-reviewed. Any opinions or recommendations discussed are solely those of the author(s) and are not endorsed by BMJ. BMJ disclaims all liability and responsibility arising from any reliance placed on the content. Where the content includes any translated material, BMJ does not warrant the accuracy and reliability of the translations (including but not limited to local regulations, clinical guidelines, terminology, drug names and drug dosages), and is not responsible for any error and/or omissions arising from translation and adaptation or otherwise.

Open access This is an open access article distributed in accordance with the Creative Commons Attribution Non Commercial (CC BY-NC 4.0) license, which permits others to distribute, remix, adapt, build upon this work non-commercially, and license their derivative works on different terms, provided the original work is properly cited, appropriate credit is given, any changes made indicated, and the use is non-commercial. See: http://creativecommons.org/licenses/by-nc/4.0/.

ORCID iD

Jidong Huang http://orcid.org/0000-0002-3425-9155

\section{REFERENCES}

1 US Department of Health and Human Services. The health consequences of smoking-50 years of progress: a report of the surgeon General. Atlanta, GA: US Department of Health and Human Services, Centers for Disease Control and Prevention, 2014.

2 US Department of Health and Human Services. The health consequences of involuntary exposure to tobacco smoke: a report of the surgeon General. Atlanta, GA: US Department of Health and Human Services, Centers for Disease Control and Prevention, 2006.

3 Centers for Disease Control and Prevention (US), Office on Smoking and Health (US). How tobacco smoke causes disease: the biology and behavioral basis for smoking-attributable disease: a report of the surgeon General. US Government Printing Office, 2010.

4 Yang G, Wang Y, Wu Y, et al. The road to effective tobacco control in China. The Lancet 2015;385:1019-28.

5 King BA, Mirza SA, Babb SD, et al. A cross-country comparison of secondhand smoke exposure among adults: findings from the global adult tobacco survey (GATS). Tob Control 2013;22:e5

6 Asma S. The GATS atlas: global adult tobacco survey 2015. 
7 Mbulo L, Palipudi KM, Andes L, et al. Secondhand smoke exposure at home among one billion children in 21 countries: findings from the global adult tobacco survey (GATS). Tob Control 2016;25:e95-100.

8 China Center of Disease Control and Prevention. Global Adult Tobacco Survey Fact Sheet - China, 2018. Available: https://www. who.int/docs/default-source/wpro-documents/countries/china/2018gats-china-factsheet-cn-en.pdf?sfvrsn=3f4e2da9 2 [Accessed 20 Feb 2020].

9 Nan Y, Xi Z, Yang Y, et al. The 2015 China Adult Tobacco Survey: exposure to second-hand smoke among adults aged 15 and above and their support to policy on banning smoking in public places]. Zhonghua Liu Xing Bing Xue Za Zhi 2016;37:810-5.

10 Fong GT, Sansone G, Yan M, et al. Evaluation of smoke-free policies in seven cities in China, 2007-2012. Tob Control 2015;24 Suppl 4:iv14-20.

11 Ye X, Yao Z, Gao Y, et al. Second-Hand smoke exposure in different types of venues: before and after the implementation of smoke-free legislation in Guangzhou, China. BMJ Open 2014;4:e004273.

12 Yang G. Tobacco control in China. Springer, 2018.

13 Chinese center for disease control and prevention. 2015 China adult tobacco survey report, 2016. Available: http://www.tcrc.org.cn/ UploadFiles/2016-03/318/201603231215175500.pdf [Accessed 28 Mar 2020].

14 Lin H, Chang C, Liu Z, et al. Subnational smoke-free laws in China. Tob Induc Dis 2019;17:78.

15 Wan X, Stillman F, Liu H, et al. Development of policy performance indicators to assess the implementation of protection from exposure to secondhand smoke in China. Tob Control 2013;22 Suppl 2:ii9-15.

16 Koplan J, Redmon P, Duan Y, et al. The role of cities in reducing smoking in China. Annals of Global Health 2015;81:36.

17 Sansone G, Fong GT, Yan M, et al. Secondhand smoke exposure and support for smoke-free policies in cities and rural areas of China from 2009 to 2015: a population-based cohort study (the ITC China survey). BMJ Open 2019;9:e031891.

18 Yu S, Duan Z, Redmon PB, et al. mHealth intervention is effective in creating smoke-free homes for newborns: a randomized controlled trial study in China. Sci Rep 2017;7:1-9.

19 Yang L, Tong EK, Mao Z, et al. A clustered randomized controlled trial to reduce secondhand smoke exposure among nonsmoking pregnant women in Sichuan Province, China. Nicotine Tob Res 2016;18:1163-70.

20 Stillman F, Navas-Acien A, Ma J, et al. Second-Hand tobacco smoke in public places in urban and rural China. Tob Control 2007;16:229-34.

21 Xia $\mathrm{C}$, Zheng $\mathrm{R}$, Zeng $\mathrm{H}$, et al. Provincial-level cancer burden attributable to active and second-hand smoking in China. Tob Control 2019;28:669-75.

22 Global Adult Tobacco Survey Collaborative Group. Tobacco questions for surveys: a subset of key questions from the global adult tobacco survey (GATS): centers for disease control and prevention. Atlanta, GA, 2011.

23 The Global Adult Tobacco Survey (GATS): sample design and related methods. Proceedings of the section on survey methods, joint statistical meetings Alexandria: American statistical association 2010.

24 Huang J, Duan Z, Wang Y, et al. Use of electronic nicotine delivery systems (ends) in China: evidence from citywide representative surveys from five Chinese cities in 2018. Int J Environ Res Public Health 2020;17:2541.

25 Redmon P, Huang J, Duan Z, et al. Secondhand smoke (SHS) exposure and perceived health risks of tobacco use among urban residents in five cities in China. Ann Glob Health 2017;83:113-4.

26 Peugh JL, Enders CK. Missing data in educational research: a review of reporting practices and suggestions for improvement. Rev Educ Res 2004;74:525-56.

27 US Centers for Disease Control and Prevention. global tobacco surveillance system data (GTSSData). Available: https://www.cdc. gov/tobacco/global/gtss/gtssdata/index.html [Accessed 5 Nov 2020].

28 Adda J, Cornaglia F. The effect of bans and taxes on passive smoking. Am Econ J Appl Econ 2010;2:1-32.

29 Ho SY, Wang MP, Lo WS, et al. Comprehensive smoke-free legislation and displacement of smoking into the homes of young children in Hong Kong. Tob Control 2010;19:129-33.

30 Yao T, Sung H-Y, Mao Z. Secondhand smoke exposure at home in rural China economics of tobacco control in China: from policy research to practice: world scientific 2016:29-42.

31 Jin Y, Wang L, Lu B, et al. Secondhand smoke exposure, indoor smoking bans and smoking-related knowledge in China. Int $J$ Environ Res Public Health 2014;11:12835-47.

32 Abdullah AS, Hua F, Xia X, et al. Second-Hand smoke exposure and household smoking bans in Chinese families: a qualitative study. Health Soc Care Community 2012;20:356-64.

33 Ji M, Ding D, Hovell MF, et al. Home smoking bans in an urbanizing community in China. Am J Prev Med 2009;37:132-6.

34 Yang T, Jiang S, Barnett R, et al. Individual and city-level determinants of secondhand smoke exposure in China. Int $J$ Health Geogr 2015;14:36.

35 Yao T, Sung H-Y, Mao Z, et al. Secondhand smoke exposure at home in rural China. Cancer Causes Control 2012;23 Suppl 1:109-15.

36 World Health Organization. Tobacco in China. Available: https://www. who.int/china/health-topics/tobacco [Accessed 20 Feb 2020].

37 World Health Organization. WHO framework convention on tobacco control: World Health Organization 2003.

38 Coughlin SS. Recall bias in epidemiologic studies. J Clin Epidemiol 1990;43:87-91.

39 Grimm P. Social desirability bias. Wiley international encyclopedia of marketing, 2010. 